\title{
COVID-19 Biomedical Waste Management: Knowledge Assessment Among Medical Professionals in a COVID-19 Dedicated Hospital, a Cross Sectional Study.
}

Aiman Perween Afsar ( $\boldsymbol{D}$ afsaraiman@gmail.com )

Maulana Azad Medical College https://orcid.org/0000-0002-1680-3559

Lovenish Bains

Maulana Azad Medical College https://orcid.org/0000-0002-8627-0452

Anurag Mishra

Maulana Azad Medical College

Aashima Dabaas

Maulana Azad Medical College

Akshit Mittal

Maulana Azad Medical College

Sulakshna Aggarwal

Maulana Azad Medical College

Daljit Kaur

All India Institute of Medical Sciences - Rishikesh

\section{Research Article}

Keywords: COVID-19, Biomedical Waste, Pandemic, Medical Professionals, Infection, Knowledge, Segregation, Assessment

Posted Date: June 14th, 2021

DOI: https://doi.org/10.21203/rs.3.rs-594227/v1

License: (c) (i) This work is licensed under a Creative Commons Attribution 4.0 International License. Read Full License 
1 COVID-19 Biomedical Waste Management: Knowledge Assessment among Medical

2 Professionals in a COVID-19 Dedicated Hospital, a Cross Sectional Study.

3 Authors: Aiman Perween Afsar ${ }^{1}$, Lovenish Bains ${ }^{2}$, Anurag Mishra ${ }^{3}$, Aashima Dabaas ${ }^{4}$,

$4 \quad$ Akshit Mittal $^{5}$, Sulakshna Aggarwal ${ }^{6}$, Daljit Kaur ${ }^{7}$

5

6 Affiliations: Medical Student ${ }^{1,5,6}$, Department of Surgery ${ }^{2,3}$, Department of Paediatrics ${ }^{4}$,

7 Maulana Azad Medical College, New Delhi, India, Department of Blood Bank \& Transfusion

8 Medicine, All India Institute of Medical Sciences, Rishikesh ${ }^{7}$

9

10 First Author: Aiman Perween Afsar

Medical Student, Maulana Azad Medical College, New Delhi, India.

Email: afsaraiman@gmail.com

Corresponding Author: Dr Lovenish Bains, Associate Professor, Department of Surgery,

Maulana Azad Medical College, New Delhi, India

Email: lovenishbains@gmail.com

1. Aiman Perween Afsar, MBBS student, Maulana Azad Medical College, New Delhi, India.

Email : $\underline{\text { afsaraiman@gmail.com }}$

2. Dr Lovenish Bains, MS, FNB, FACS, Associate Professor, Department of Surgery, Maulana Azad Medical College, New Delhi, India

Email: lovenishbains@gmail.com 
3. Dr Anurag Mishra, MS, DNB,FACS, Associate Professor, Department of Surgery, Maulana Azad Medical College, New Delhi, India

Email :anurag.alok@gmail.com

4. Dr Aashima Dabaas, MD, Associate Professor, Department of Pediatrics, Maulana Azad Medical College, New Delhi, India.

Email : dr.aashimagupta@gmail.com

5. Akshit Mittal, MBBS student, Maulana Azad Medical College, New Delhi, India. Email : $\underline{\text { akshitmittal420@gmail.com }}$

6. Sulakshna Aggarwal, MBBS student, Maulana Azad Medical College, New Delhi, India

Email : $\underline{\text { Sulakshana1999sa@gmail.com }}$

7. Daljit Kaur, MD, Department of Blood Bank \& Transfusion Medicine, All India Institute of Medical Sciences, Rishikesh

Email: doc.daljit@gmail.com

\section{ABSTRACT}

Background

Nations have faced significant challenges with the COVID-19 related biomedical waste since its outbreak. Before the pandemic, Indian hospitals typically generated 500g of BMW per bed each day, which has now risen to about 2.5-4 kg per bed per day. Proper BMW aims to reduce waste generation, ensures efficient collection, handling and safe disposal that it controls infection and improves safety for the medical professionals. Hence, the present study was conducted to assess the level of knowledge among medical professionals regarding biomedical 
47 waste segregation, transport and treatment and thereafter provide constructive suggestions to reduce mismanagement practices.

49

50

\section{Methodology}

An e-survey was done to assess the knowledge and awareness of management of Biomedical Waste generated due to COVID-19 among Medical Professionals (students, residents and consultants) of tertiary care hospital of North India.

\section{Result}

The average knowledge score about BMW waste generated due to COVID-19 was found to be: for segregation $-27.46 \%, 59.615 \%$, and $49.8 \%$; transport of waste from site of generation to the site of disposal- $63.66 \%, 89.1 \%$ and $95.2 \%$; disposal of waste generated- $29 \%, 71.96 \%$, and $68.24 \%$ in students, residents, and consultants respectively. Overall, the knowledge score was $41.4 \%, 67.98 \%$, and $61.34 \%$ among the students, residents and consultants respectively. We found that participants with greater years of experience (residents and consultants) had better knowledge compared to that of the students $(\mathrm{p}<0.05)$.

\section{Discussion}

Our study found that the mean score was $56.9 \%$ which is comparably more than the knowledge score of few Low and Middle Income Countries but less than the knowledge score of some European countries. Studies have found that the chances of infection directly correlates with the low level of knowledge. This underlines that training aspects of health-care waste management should be strengthened, not only for the practising medical professionals but also of the students so that the current, existing, and future regulations are practiced diligently and uniformly. Hence, it is of paramount importance that we strengthen the training aspects of not only the practising medical professionals but also of the students. Periodic evaluation and assessment should become routine to enforce adherence to waste management. 
Keywords: COVID-19, Biomedical Waste, Pandemic, Medical Professionals, Infection, Knowledge, Segregation, Assessment

\section{Background}

The global pandemic, that began in November, 2019, from Wuhan, China ${ }^{1}$ has affected more than 170 million people around the world with over 3.5 million deaths as on May 31, 2021, says a report from Coronavirus Resource Center, Johns Hopkins University. India alone has reported more than 28 million cases, as on May $31,2021 .^{2}$

Amidst the coronavirus disease 2019 (COVID-19) pandemic, health care settings are experiencing high demand of Personal Protective Equipment (PPE) from all strata of health care workers, to protect themselves from infection and also owing to fear of infection. Almost all COVID-19 related waste cannot be reused, adding to increased biomedical waste(BMW). One of the direct consequences of the pandemic has been a 40 per cent increase in the global production of biomedical waste. ${ }^{0}$ Analysis revealed that on an average, each COVID-19 infected patient in India generates approximately $3.41 \mathrm{~kg} / \mathrm{d}$ of BMW and average proportion of yellow BMW (which is highly infectious) in it is $50.44 \% .^{3}$

Massive amounts of medical waste have already been generated and disposed of into the natural environment ${ }^{4}$ and waste mismanagement practices can increase the contamination risks in developing countries. ${ }^{5}$ At this time of crisis, with limited resources and manpower available, these are difficult to store and transport. ${ }^{6}$

The hospital waste management has diverse ramifications as it not only affects the health of patients but also of medical professionals (doctors, nurses, sanitary staff, etc.) and general public. Inadequate and inappropriate knowledge of handling of biomedical waste may have 
serious health consequences and a significant impact on the environment. ${ }^{7}$ The common use of surgical facemask and hand gloves is being largely consumed and due to their size and lightweight, there is a chance that these wastes may be disposed of with other solid waste. It is also essential to guarantee that this waste doesn't mix with regular household waste. Since COVID-19 gets transmitted through direct touch and tainted surfaces and items ${ }^{8}$, it could even speed up the growth of COVID-19 in developing countries that lacks appropriate resources to handle the waste. It could lure rag pickers as it is an access for some quick money. Some studies also reported the illegal resale and reuse of BMW $.9,{ }^{10},{ }^{11}$

Medical waste management issues are less examined in India due to poor details and waste statistics data. This indicated the need to have a comprehensive waste management strategy as well as raising awareness among all those involved either in the generation, segregation or treatment of COVID-19 waste. On this background, this paper aims to provide an assessment of knowledge of medical professionals for segregation, transportation, treatment and final disposal of biomedical waste, especially during increased waste generation of COVID-19 pandemic as they are directly involved in the management of COVID-19 patients in assessing, clinical examination, sampling, and treatment.

\section{Methodology}

It was an e-survey based study. The study involved undergraduate students and the frontline healthcare workers, i.e., Medical Officers, Interns, Post Graduates, Senior Residents, and Consultants at a dedicated COVID-19 facility in Delhi which is also one of the largest teaching tertiary care hospitals in India. The ethical clearance for the study was obtained from the Institutional Ethics Committee. The sample size was calculated to be 323, with a confidence level of $95 \%$ in a population size of 2000 healthcare professionals. A questionnaire using the 
119 Google form was made. A scoring system was added which awarded points for correct answer.

120 The questionnaire was divided into 4 sections. The first section Q 1-10) collected demographic details of the participants. The next section (Q 11-17) assessed knowledge of the participants

122 regarding management and policies of Biomedical wastes. The third section $(\mathrm{Q}$ 18-33 with

123 subsections) tested the knowledge regarding segregation, transport, treatment and final disposal 124 of waste. The last section(Q 34-38) sought the opinion on the waste management practices prevalent in their hospitals and their suggestions on how to improve on them. This questionnaire was shared with the medical professionals via E-mail and other social networking website such as-WhatsApp. Participation in the survey was purely voluntary and anonymous. On submission of the form, the participants were directed to Infection control manual and guidelines from $\mathrm{WHO}^{12}, \mathrm{CDC}^{13}$, ICMR for their perusal and awareness. A reminder was sent after 15 days, to participate in the study. The data were collected and assessed statistically by Google form, Google Sheets, Microsoft Excel. Chi square test was used to compare proportions across different groups.

\section{Results}

The survey was sent to around 825 people and the response percentage was $50.42 \%$ (416 participants). Out of the 416 participants, $22.35 \%$ (93) participants were directly involved in

137 COVID-19 care(Table 1). 83\% of these participants had received training or read guidelines for management of biomedical waste, in general whereas only $34.4 \%$ were aware about management of Biomedical waste generated by COVID-19 waste. Though 92.5\% (385) participants thought it is important to know about biomedical waste generation, hazards, and legislation, yet only $42 \%$ were aware of the government's regulations and legislation on COVID-19 waste management. 86.6\% (360) were aware how inadequate management of COVID-19 waste can lead to cross infection. We found that only $27.46 \%$ students knew about 
the correct methods of segregation of waste, whereas $59.6 \%$ of residents and $49.8 \%$ consultants were aware of the correct methods (Table 2). With regards to transport of waste, $67 \%$ of the students and more than $90 \%$ of experienced medical professionals are aware that only licensed personnel can transport the waste (Table 3). The knowledge regarding disposal and treatment of liquid waste is lacking in all strata (knowledge score found to be $60 \%$ in residents and $26 \%$ among students) (Table 4). Overall, there was significant difference in the knowledge of the students (knowledge score was found to be $41.4 \%$,) and the experienced medical professionals (67.98\%, and $61.34 \%$ among the residents and the consultants respectively).

\section{Discussion}

In India, 103 billion ton of plastic waste has been produced during the pandemic in 2020 , which is second only to China that produced around 108 billion ton of plastic waste. ${ }^{14}$ Delhi generated 382 tonnes of COVID-19 bio-medical waste in September 2020, according to the CPCB data. ${ }^{15}$ As the pandemic continues, so will the waste, and keeping that garbage safe and contained will continue to be a challenge for communities until the crisis is over. ${ }^{16}$ In our study, we found that $86.6 \%$ were aware how inadequate management of COVID-19 waste can lead to cross infection. Ahmed MA while evaluating knowledge of cross infections in dentists during COVID-19 pandemic found that $80 \%$ participants agreed that proper disposal of waste is crucial for cross-infection control. ${ }^{17}$

In a study in Thailand conducted to assess the knowledge of medical professionals regarding BMW management, the overall scores were found to be at a higher level $(89.5 \%) .{ }^{18}$ Similarly, the average knowledge score in three Low- and Middle-Income countries Ethiopia, Nigeria and Sri Lanka were found to be $56.8 \%, 45 \%$ and $40.5 \%$, respectively. ${ }^{19},{ }^{20},{ }^{21}$ 
The improper disposal of COVID-19 bio-medical waste poses severe risks to public health and the environment as it acts as a host of variety of pathogenic microorganisms. Pathogens present in BMW, if not managed well, may enter the human body through a puncture, abrasion or cut in the skin, mucous membrane, inhalation, and ingestion. Emphasis must be laid on the proper management of waste generated in the course of COVID-19 treatment. It has found that there are gaps in knowledge and practice in the implementation of BMW management protocol. ${ }^{22} \mathrm{~A}$ systematic review of the literature reported that the pooled prevalence of healthcare associated infection was $7.6 \%$ in high-income countries and $10.1 \%$ in low and middle-income countries where average knowledge score was low. ${ }^{23}$ Studies also found that, in Africa including Ethiopia, the prevalence of hospital-acquired infection was significantly high (12-35\%). ${ }^{24},{ }^{25},{ }^{26},{ }^{27}$ Thus, significant relation can be established between level of knowledge among healthcare professionals regarding BMW management and healthcare associated infection.

The most essential step to Biomedical Waste Management is sequential handling, that is Generation $\rightarrow$ Segregation/Separation $\rightarrow$ Collection $\rightarrow$ Transportation, storage $\rightarrow$ Treatment $\rightarrow$ Final disposal. The proper awareness of the long process of handling of waste, can help to minimize infections in persons at risk, esp. those who the handle of waste. We found that $92.2 \%$ of the residents knew about the correct sequence whereas only $64 \%$ of students were aware. Due to the ravaging pandemic, the Government of India has decided to utilize the services of students, therefore students must possess adequate knowledge about management of BMW for proper disposal of COVID-19 Infected waste and their own safety. Although there are rules and regulations for Biomedical Waste Management, adherence to the basic rules of biomedical waste, segregation and management is still low in India. ${ }^{28} \mathrm{We}$ found that only $27.46 \%$ students knew about the correct methods of segregation of waste, whereas $59.6 \%$ of residents and $49.8 \%$ consultants were aware of the correct methods(Table 2). Our results were better as only $30 \%$ of the participants had knowledge regarding segregation of the hospital in one study. ${ }^{29}$ 
Knowledge was found to be less compared to other study of Ethiopia, where $83.9 \%$ doctors had knowledge about the correct ways of segregation of waste. ${ }^{18}$

In our study, we found that there were gaps in knowledge about the fate of the waste after it was segregated, followed by how were they treated and the safe transportation of biomedical waste from the hospital. This is comparable to another study where knowledge score was $64 \%$ amongst students ${ }^{30}$. In a survey done in China in times of COVID-19 pandemic, it was found that the majority proportion $(37.8 \%)$ were non-compliant to guidelines related to the management of medical waste. Out of these, $71.4 \%$ of respondents lacked knowledge of proper disposal, collection of waste. ${ }^{31}$ With regards to transport of waste, we found that about $67 \%$ of the students and more than $90 \%$ of experienced medical professionals are aware that only licensed personnel can drive the waste to the final disposal site.(Table 3). 77\% students and 90\% trained healthcare workers are aware that personnel involved in BMW handling should wear appropriate gear, including boots, aprons, long-sleeved gowns, thick gloves, masks, and goggles or face shields, according to recommendations from the World Health Organization ${ }^{32}$. Data used from Hospital Infection Control(HIC) manual helped in assessment of knowledge regarding management and treatment of spills, liquid waste, shared toilets, and certain possessions such as garments, phones, mattress. The knowledge amongst experienced medical professionals is found to be excellent (approximately 96\%) regarding management of spills, whereas, students are not quite well aware (average score $=67 \%)($ Table 4$)$. Students must be provided training to combat these frequently encountered situations such as spills. Our questionnaire also aimed to assess the knowledge regarding the proper method of disposal of homemade masks, waste containers, anatomical waste, IV tubes, catheter, syringe, sharps, vials, soiled gloves, dressings, PPE kits and liquid wastes. Only $44.28 \%$ of students knew about the right methods of disposal and treatment of waste whereas, $72 \%$ residents and $68 \%$ 
consultants answered these questions correctly. (Table 4). Correct knowledge about treatment of these wastes is lacking in all strata. Low level of awareness regarding final disposal of wastes, not only increases the risk of infectivity once waste has left hospitals, but also has adverse environmental impact, in the form of soil pollution. Added to this issue are the increase in the use of single-use plastic, and the reduction of plastic recycling due to the curfew generated by the pandemic, further aggravating plastic pollution. ${ }^{33}$

Significant relation was found between years of experience and knowledge score (Figure 2). Trained professionals had higher knowledge score $(67.98 \%$, and $61.34 \%$ among the residents and consultants respectively) as compared to that of students (41.4\%). Low level of knowledge has direct implication on waste management practices. Mismanaged BMW can lead to infection spread. From the results, it has become clear that there is still a need to educate the students and residents about the problem of biomedical waste. Healthcare professionals are the key workers in the management of BMW generated by health care practices, and the management of the COVID-19 waste is all the more essential to reduce its infectivity and spread across the country. Unless the healthcare professionals are aware, it cannot be ensured that the waste ended up at the right place. Thus, providing training is a very critical step to reduce waste generation and cost saving. According to a study conducted in Spain, there was a significant reduction in the monthly average health care waste volume of $6.2 \%$, after an interventional training. Significant differences regarding BMW segregation before and after the intervention $(\mathrm{p}<0.05)$ were found. The significant BMW weight reduction and the improvement of waste classification also helped reduce monthly expenditure by $€ 125,205$. $^{34}$ Another study by El-Sharkawy, also reported significant improvement of knowledge from $25 \%$ to $78 \%$ after the educational intervention. ${ }^{35}$

Repeated and comprehensive training (starting with induction of all new appointees to once a year thereafter) should be done. The right practices in the form of avoiding of injuries, 
importance of vaccinations and following of universal regulations for waste management should be promoted. Although Central Pollution Control Board has made it mandatory for all healthcare centers to display signages for Biomedical Waste Management, around $35 \%$ of participants said that there were no signages displayed in their institution. This highlights intervention of administration to bring about a change. $90 \%$ of the participants think it is difficult to remember the steps for management. Therefore, it becomes more essential to put up signages at all required sites.

Table 5: Framework for BMW Management in COVID-19 $\mathrm{era}^{36}$ (based on WHO multimodal 250 strategy)

\begin{tabular}{|l|l|}
\hline 1. Build it & $\begin{array}{l}\text { Build an HIC committee with dedicated trained professionals and multi- } \\
\text { disciplinary team for the management of biomedical waste } \\
\text { Administrating support to ensure availability and accessibility of colour } \\
\text { coded garbage bins }\end{array}$ \\
\hline 2. Teach it & $\begin{array}{l}\text { Training and education of individuals, especially the younger medical } \\
\text { workforce } \\
\text { It should be made compulsory for healthcare facilities to get their } \\
\text { healthcare personnel (medical and paramedical staffs) trained inhouse HIC } \\
\text { committee. } \\
\text { Regular monitoring and feedback by periodic assessment among Medical } \\
\text { Professionals } \\
\text { Regular audit to identify deficient areas } \\
\text { Remain updated with latest evidence and guidelines }\end{array}$ \\
\hline
\end{tabular}




\begin{tabular}{|l|l|}
\hline 4. Sell it & $\begin{array}{l}\text { Easy readout placards/posters placed at point of generation and segregation } \\
\text { in wards and other areas } \\
\text { Using promotional/reinforcing messages } \\
\text { Planning for periodic campaigns }\end{array}$ \\
\hline 5. Live it & $\begin{array}{l}\text { Adequate measures for biomedical waste management should become a } \\
\text { part of institutional culture and propagated regularly }\end{array}$ \\
\hline
\end{tabular}

\section{Strengths and Limitations}

It is one of its kind surveys about Biomedical Waste especially in the time of COVID-19. A scoring system was used that helped understand the shortcomings and correct answers were provided to rectify them. Firstly, the response rate to the survey(50.42\%) was moderate, in line with other studies. The survey participation rate was good among the students. Secodly, there is lack of studies in this subject in the indian context; when COVID-19 waste segregation and disposal awareness is the need of the hour. This assessment is useful due to poor available data of medical waste flow of Biomedical Waste generated due to COVID-19. Lastly, our study also assessed the knowledge of students who are also going to be recruited for COVID-19 management in hospitals. Hence, an evaluation of their gap of knowledge becomes of paramount importance to reduce cross-infection by mishandled Biomedical Waste.

Our study also had a few limitations. Firstly, response rate was moderate among residents and less response rate was observed from consultants. Secondly, it is a single centre study, the results cannot be generalized at a national level. As this is a questionnaire-based online survey with voluntary participation and those who did not participate may be systematically different from those who participated, thus the possibility of respondent bias cannot be ruled out. The 
survey was essentially for doctors; however, the nursing and paramedical staff also must possess adequate knowledge and awareness about BMW management.

271

\section{Conclusion}

273 Overall, the knowledge score was found to be $41.4 \%, 67.98 \%$, and $61.34 \%$ among the students, 274 residents and consultants respectively. Low level of knowledge has been shown to have direct 275 impact on infection spread. Thus, it is of paramount importance to dispose of the COVID-19 waste carefully to prevent spread of infection. Training aspects of health-care waste

277 management should be strengthened so that the current, existing, and future regulations are 278 practiced diligently and uniformly. Periodic evaluation and assessment should become routine 279 to enforce adherence to waste management. Strict implementation of biomedical waste management rules is the need of the hour.

282 Abbreviations

283 COVID-19 - Coronavirus Disease-19 PPE- Personal Protective Equipment

BMW- Biomedical Waste

WHO- World Health Organization

CDC- Centers for Disease Control and Prevention

ICMR- Indian Council of Medical Research

CPCB- Central Pollution Control Board

HIC- Hospital Infection Control

\section{Legends}

293 Table 1: Demographic Details and Assessment of General Information 
Table 2: Average Score among Participants regarding Segregation of Waste

295

296

297

298

299

300

301

302

303

304

305

306

307

308

309

310

311

312

313

314

315

316

317

Table 3: Average Score among Participants regarding Transport of Waste

Table 4: Average Score among Participants regarding Final Treatment

Table 5: Framework for BMW Management in COVID-19 era

Figure 1: Comparison of Scores among Students, Residents and Consultants

Figure 2: Comparison of Scores based on Years of Clinical Experience

\section{Declarations}

\section{Ethics Approval and consent to participation}

The ethical approval was obtained from the Institutional Ethics Committee of Maulana Azad Medical College. Consent for the participation was incorporated in the survey questionnaire, only those who consented were eligible to participate.

\section{Consent for Publication}

Consent for the publication was incorporated in the survey questionnaire, only those who consented were eligible to participate.

Availability of Data and Materials

Not available.

\section{Competing Interest}

The authors declare that they have no competing interests. 
319 None.

320

321

\section{Authors' Contributions}

322 LB and APA conceptualized the manuscript. APA and LB designed the study, co-ordinated 323 the execution of the study. APA, LB and AKM reviewed the literature, analyzed data, and 324 made major contribution to the writing of the manuscript. LB, AM, AD supervised the

325

326

327

328

329

330

331

332

333

\section{Acknowledgement}

We would like to thank the institution, Maulana Azad Medical College \& Lok Nayak Hospital and Gurukool for providing us a great opportunity to conduct this study. We medical students sincerely thank our mentors for helping us take this study and guiding us at each step. 


\footnotetext{
${ }^{1}$ WHO Timeline - COVID-19. Available online < https://www.who.int/news/item/27-042020-who-timeline---COVID-19 > Last accessed on 2020, May 6

2 Johns Hopkins University And Medicine, Coronavirus Resource Centre. 2020 December 15; Available from < https://coronavirus.jhu.edu/ > Last accessed on 2021, May 31

${ }^{3}$ Thind PS, Sareen A, Singh DD, Singh S, John S. Compromising situation of India's biomedical waste incineration units during pandemic outbreak of COVID-19: Associated environmental-health impacts and mitigation measures. Environ Pollut. 2021 May 1;276:116621. doi: 10.1016/j.envpol.2021.116621.

${ }^{4}$ Saadat S, Rawtani D, Hussain CM. Environmental perspective of COVID-19. Sci Total Environ. 2020;728:138870. doi:10.1016/j.scitotenv.2020.138870

${ }^{5}$ Nzediegwu C, Chang SX. Improper solid waste management increases potential for COVID-19 spread in developing countries. Resour Conserv Recycl. 2020;161:104947. doi:10.1016/j.resconrec.2020.104947
}

${ }^{6}$ Das A, Garg R, Ojha B, Banerjee T. Biomedical Waste Management: The Challenge amidst COVID-19 Pandemic. J Lab Physicians. 2020 Aug;12(2):161-162. doi: 10.1055/s-00401716662.

7 Mathur V, Dwivedi S, Hassan M, Misra R. Knowledge, Attitude, and Practices about Biomedical Waste Management among Healthcare Personnel: A Cross-sectional Study. Indian J Community Med. 2011;36(2):143-145. doi:10.4103/0970-0218.84135

${ }^{8}$ Ramteke S, Sahu BL. Novel coronavirus disease 2019 (COVID-19) pandemic: Considerations for the biomedical waste sector in India. https://doi.org/10.1016/j.cscee.2020.100029

${ }^{9}$ Ananth AP, Prashanthini V, Visvanathan C. Healthcare waste management in Asia. Waste Manag. 2010;30(1):154-161. doi:10.1016/j.wasman.2009.07.018

${ }^{10}$ Mujeeb SA, Adil MM, Altaf A, Hutin Y, Luby S. Recycling of injection equipment in Pakistan. Infect Control Hosp Epidemiol. 2003;24(2):145-146. doi:10.1086/502175

${ }^{11}$ Verma LK, Mani S, Sinha N, Rana S. Biomedical waste management in nursing homes and smaller hospitals in Delhi. Waste Manag. 2008;28(12):2723-2734.

doi:10.1016/j.wasman.2007.12.013

${ }^{12}$ https://www.who.int/emergencies/diseases/novel-coronavirus-2019/technicalguidance/infection-prevention-and-control . Last accessed on 2020, May 6

${ }^{13}$ Environmental Infection Control Guidelines. Available from https://www.cdc.gov/infectioncontrol/guidelines/environmental/background/medicalwaste.html . Last accessed on June 2, 2021

${ }^{14}$ Benson NU, Bassey DE, Palanisami T. COVID pollution: impact of COVID-19 pandemic on global plastic waste footprint. Heliyon. $2021 \mathrm{Feb}$;(2):e06343. doi:

10.1016/j.heliyon.2021.e06343. 
${ }^{15}$ India's COVID-19 biomedical waste woes enormous: 150 tn waste generated daily.; Available from < https://indyatv.in/news-briefs/indias-COVID-19-biomedical-waste-woesenormous-150-tn-waste-generated-daily/ > Last accessed on 2020 , October 13

${ }^{16}$ Calma J. The COVID-19 pandemic is generating tons of medical waste. 2020 Mar 26 ; Available from https://www.theverge.com/2020/3/26/21194647/the-COVID-19-pandemicis-generating-tons-of-medical-waste> Last accessed on 2020, April 27

${ }^{17}$ Ahmed MA, Jouhar R, Adnan S, Ahmed N, Ghazal T, Adanir N. Evaluation of Patient's Knowledge, Attitude, and Practice of Cross-Infection Control in Dentistry during COVID-19 Pandemic. Eur J Dent. 2020 Dec;14(S 01):S1-S6. doi: 10.1055/s-0040-1721295. Epub 2020 Dec 15.

${ }^{18}$ Akkajit P, Romin H, Assawadithalerd M. Assessment of Knowledge, Attitude, and Practice in respect of Medical Waste Management among Healthcare Workers in Clinics

${ }^{19}$ Deress T, Hassen F, Adane K, Tsegaye A. Assessment of Knowledge, Attitude, and Practice about Biomedical Waste Management and Associated Factors among the Healthcare Professionals at Debre Markos Town Healthcare Facilities, Northwest Ethiopia. J Environ Public Health. 2018;2018:7672981. Published 2018 Oct 2. doi:10.1155/2018/7672981

${ }^{20}$ Sabageh A., Adeomi A., Adediran O., Abodunrin O., Oladimeji O., Eunice F. Perception and practices of healthcare workers in south-western Nigeria towards healthcare waste management. British Journal of Medical and Health Research. 2015;2:19-26.

${ }^{21}$ Samarakoon MA, Gunawardena NS. An evaluation of healthcare waste management in base hospitals of Colombo district. Journal of the College of Community Physicians of Sri Lanka. 2011;16(2):15-20. doi: 10.4038/jccpsl.v16i2.4576.

${ }^{22}$ Mehrotra S, Jambunathan P, Jindal M, Gupta A, Kapoor K. A cross-sectional survey to assess the knowledge regarding coronavirus disease (COVID-19) among health care professionals. Med J Armed Forces India. 2020 Aug 15. doi: 10.1016/j.mjafi.2020.07.001.

${ }^{23}$ Allegranzi B, Bagheri Nejad S, Combescure C, et al. Burden of endemic health-careassociated infection in developing countries: systematic review and meta-analysis. Lancet. 2011;377(9761):228-241. doi:10.1016/S0140-6736(10)61458-4

${ }^{24}$ Jroundi I, Khoudri I, Azzouzi A, et al. Prevalence of hospital-acquired infection in a Moroccan university hospital. Am J Infect Control. 2007;35(6):412-416.

doi:10.1016/j.ajic.2006.06.010

${ }^{25}$ Ogwang M, Paramatti D, Molteni T, et al. Prevalence of hospital-associated infections can be decreased effectively in developing countries. J Hosp Infect. 2013;84(2):138-142. doi:10.1016/j.jhin.2013.02.016

${ }^{26}$ Kallel H, Bahoul M, Ksibi H, et al. Prevalence of hospital-acquired infection in a Tunisian hospital. J Hosp Infect. 2005;59(4):343-347. doi:10.1016/j.jhin.2004.09.015 
${ }^{27}$ Yallew WW, Kumie A, Yehuala FM. Risk factors for hospital-acquired infections in teaching hospitals of Amhara regional state, Ethiopia: A matched-case control study. PLoS One. 2017;12(7):e0181145. Published 2017 Jul 18. doi:10.1371/journal.pone.0181145

${ }^{28}$ Singh P. Biomedical hazard: Untended challenge of pandemic- COVID-19. 2020 May 2; Available from <https://www.nationalheraldindia.com/health/biomedical-hazard-untendedchallenge-of-pandemic-covid-19> Last accessed on 2020, May 6

${ }^{29}$ Bathma V, Agarwal S, Sinha U, Gupta G, Khare N. Effect of Educational Intervention on Postgraduates Regarding Bio-Medical Waste Management (BMW) at a Tertiary Care Teaching Hospital, Bhopal

${ }^{30}$ Rao D, Dhakshaini MR, Kurthukoti A, Doddawad VG. Biomedical Waste Management: A Study on Assessment of Knowledge, Attitude and Practices Among Health Care Professionals in a Tertiary Care Teaching Hospital. DOI : https://dx.doi.org/10.13005/bpj/1543

${ }^{31}$ Choi UY, Kwon YM, Kang HJ, Song JH, Lee HY, Kim MS et al. Surveillance of the infection prevention and control practices of healthcare workers by an infection control surveillance-working group and a team of infection control coordinators during the COVID19 pandemic. J Infect Public Health. 2021 Apr;14(4):454-460. doi: 10.1016/j.jiph.2021.01.012.

32 Technical brief- WHO Water, sanitation, hygiene, and waste management for the COVID19 virus: Interim guidance COVID-19: Infection prevention and control / WASH. 2020 Apr 23; Available from <https://www.who.int/publications-detail/water-sanitation-hygiene-andwaste-management-for-covid-19>. Last accessed on 2020, May 6

${ }^{33}$ Ardusso M, Forero-López AD, Buzzi NS, Spetter CV, Fernández-Severini MD. COVID-19 pandemic repercussions on plastic and antiviral polymeric textile causing pollution on beaches and coasts of South America. Sci Total Environ. 2021 Apr 1;763:144365. doi: 10.1016/j.scitotenv.2020.144365.

${ }^{34}$ Mosquera M, Andrés-Prado MJ, Rodríguez-Caravaca G, Latasa P, Mosquera ME. Evaluation of an education and training intervention to reduce health care waste in a tertiary hospital in Spain. Am J Infect Control. 2014;42(8):894-897. doi:10.1016/j.ajic.2014.04.013

${ }^{35}$ El-Sharkawy GF. Effect of an educational programme about medical waste management on awareness of internship physicians in Zagazig University hospitals. Zagazig J Occup Health Safety 2009;2:10-16

36 ipc-cc-mis.pdf . Available from: https://www.who.int/infectionprevention/publications/ipc-cc-mis.pdf?ua=1 . Last accessed on May 10, 2021 
Figures

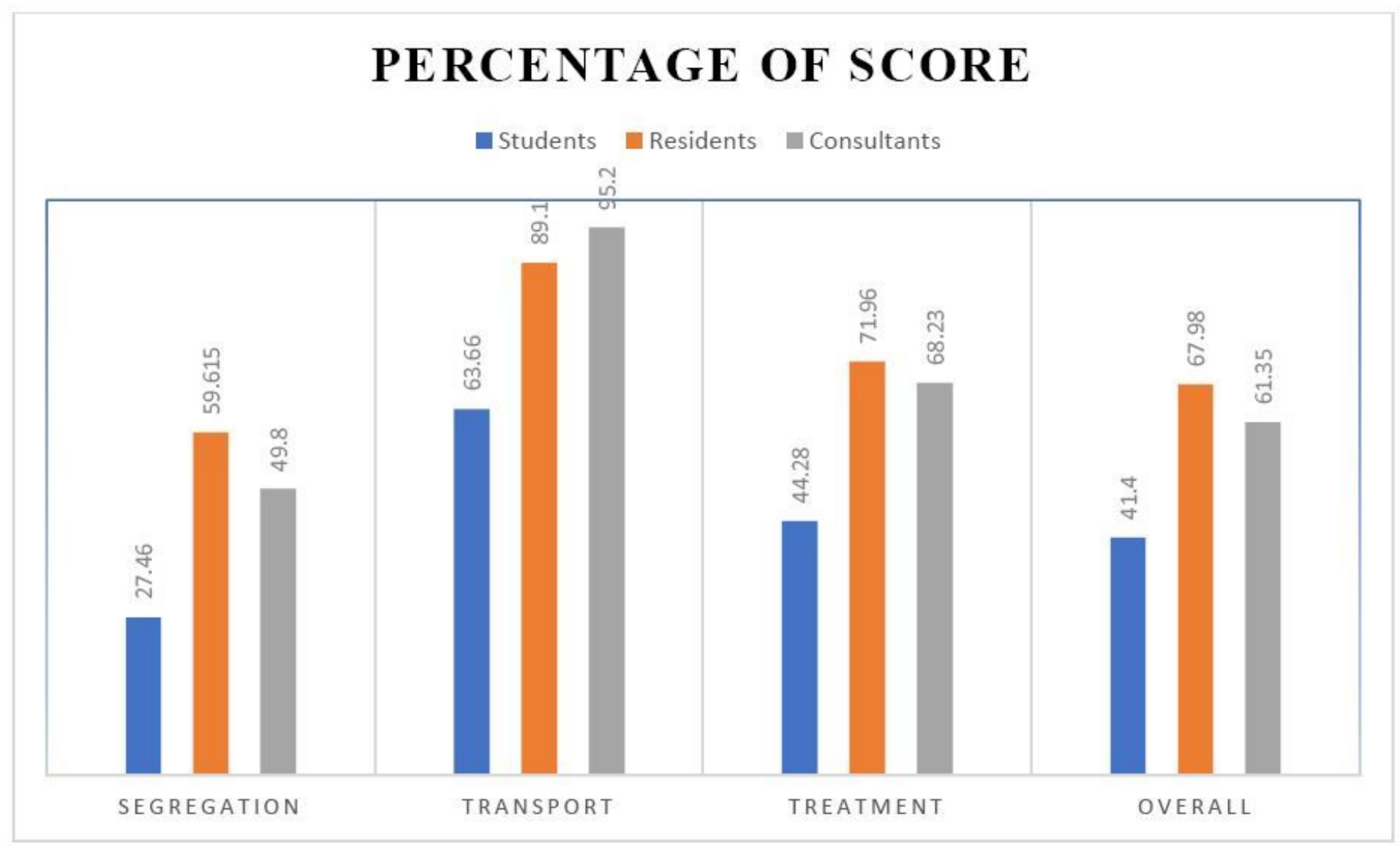

Figure 1

Comparison of Scores among Students, Residents and Consultants 


\section{Comparison of Score based on Years of Experience}

$80.00 \%$

$70.00 \%$

$60.00 \%$

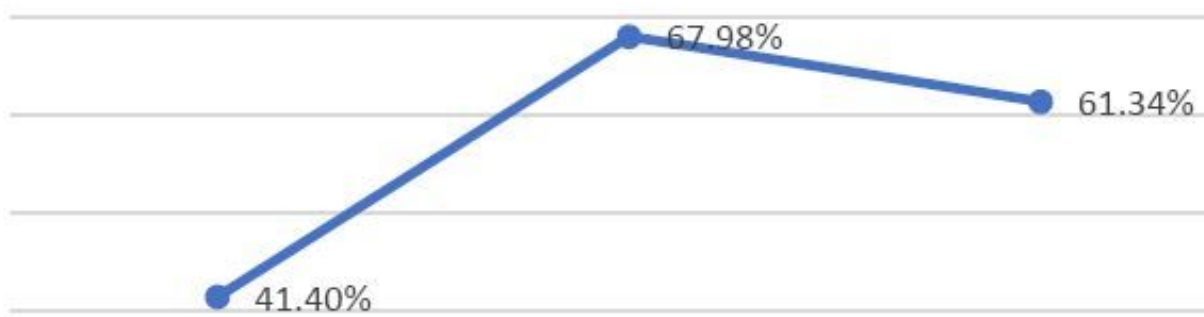

$40.00 \%$

$41.40 \%$

$30.00 \%$

$20.00 \%$

$10.00 \%$

$0.00 \%$

Students (No Experience) Residents (Experience Consultants (Experience

$<10$ years)

$>10$ years)

Figure 2

Comparison of Scores based on Years of Clinical Experience

\section{Supplementary Files}

This is a list of supplementary files associated with this preprint. Click to download.

- table1.pdf

- table2.pdf

- table3.pdf

- table4.pdf

- table5.pdf 